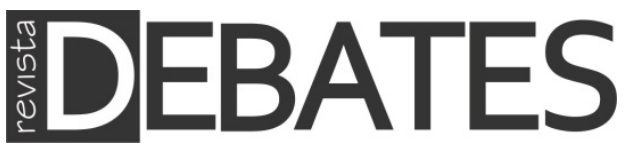

\title{
Os sentimentos explicam as escolhas dos eleitores?
}

\author{
Do feelings explain the choices of voters?
}

\section{Adriano Oliveira \\ Carlos Gadelha \\ Simara Costa}

\section{Resumo}

A hipótese central deste artigo é que os eleitores têm sentimentos para com candidatos e estes motivam suas escolhas. Este artigo tem o objetivo de comprovar a hipótese apresentada. Saudades, entusiasmo e medo são os sentimentos dos sufragistas abordados, os quais foram extraídos de diversas pesquisas de opinião realizadas no estado de Pernambuco durante a eleição presidencial de 2014. Para a comprovação da hipótese sugerida, utiliza-se a estatística descritiva e modelos estatísticos. Estudos sobre os sentimentos dos eleitores são escassos na produção científica brasileira. Este artigo procura preencher tal vazio e incentivar novos trabalhos sobre os sentimentos dos eleitores.

\section{Palavras-chave}

Eleição Presidencial; Eleitores; Escolhas; Sentimentos.

\section{Abstract}

The central hypothesis of this article is that voters have feelings for candidates who motivate their choices. This article aims to prove the hypothesis presented. Longing, excitement and fear are the feelings of the covered suffragettes, which were extracted from various opinion polls conducted in the state of Pernambuco during the presidential election of 2014. To test the hypothesis suggested, we use descriptive statistics and statistical models. Studies on the feelings of voters are scarce in Brazilian scientific production. This article seeks to fill this gap and to encourage further work on feelings of voters.

\section{Keywords}

Presidential Election; Voters; Choices; Feelings. 


\section{Introdução}

As eleiçôes presidenciais brasileiras são sistematicamente explicadas pelos determinantes do voto. Tais explicaçôes têm contribuído para elucidar as razóes das escolhas dos eleitores. Avaliação da administração, ideologia, preferência partidária e bem-estar econômico são os determinantes costumeiramente utilizados (CARREIRÃO, 2002; LOURENÇO, 2007; OLIVEIRA, 2014; PEIXOTO e RENNÓ, 2011; SINGER, 2000).

Entretanto, Pimentel Júnior (2007 e 2010) faz a opção de utilizar os sentimentos dos eleitores como variáveis que decifram a escolha dos sufragistas. Nesse sentido, o autor utiliza os sentimentos entusiasmo e ansiedade para decifrar o comportamento dos eleitores na eleição presidencial de 2006. O autor insere os sentimentos na agenda de pesquisa sobre as disputas presidenciais brasileiras.

Elster (1997 e 1998), Lavareda (2009), Oliveira e Gadelha (2012), Pimentel Júnior (2007 e 2010), Rezende e Coelho (2010), Thamm (2006), Sampaio (2014) e Westen (2007) são autores que influenciam a construção do problema deste artigo: Os sentimentos saudade, entusiasmo e medo explicam as escolhas dos eleitores?

Para contemplar o objetivo apresentado, utilizar-se-á uma série de sete pesquisas presidenciais realizadas pelo Instituto de Pesquisa Maurício de Nassau (IPMN) e Cenário Inteligência no estado de Pernambuco durante o processo eleitoral de $2014^{1}$. Tais pesquisas sugerem a seguinte hipótese: A identificação dos sentimentos dos eleitores com os competidores durante a trajetória eleitoral permite decifrar as razóes das suas escolhas.

Foram aplicados, em cada pesquisa, 2.500 questionários entre os eleitores pernambucanos. $\mathrm{O}$ universo amostral foi composto por eleitores com 16 anos, ou mais, de idade, residentes na área de abrangência. A amostra foi selecionada a partir de um plano de amostragem estratificada de conglomerados em dois estágios. No primeiro estágio, foram sorteados os setores censitários e, em seguida, é selecionado um número fixo de pessoas segundo cotas amostrais das variáveis sexo e faixa etária. O número de entrevistas foi estabelecido com base em uma amostragem aleatória simples com um nível estimado de $95 \%$ de confiança e uma margem de erro estimada de 2,2 pontos percentuais. A amostra foi definida com base nas fontes oficiais de dados: Censo IBGE, TSE e TRE. ${ }^{2}$

\footnotetext{
${ }^{1}$ Agradecemos ao IPMN e à Empresa Cenário Inteligência a disponibilização das pesquisas eleitorais.

${ }^{2}$ IBGE - Instituto Brasileiro de Geografia e Estatística; TSE - Tribunal Superior Eleitoral; TRE Tribunal Regional Eleitoral.
} 
Este artigo, na primeira parte, disserta sobre os sentimentos dos eleitores. Em seguida, apresenta as associaçôes estatísticas entre os sentimentos e a escolha do eleitor. Mostra, pela regressão logística multinomial, o sentimento que tem o maior poder explicativo da escolha dos eleitores. Na última parte, argumentamos em torno da hipótese do artigo.

Mostrar que os sentimentos são variáveis que explicam a escolha do eleitor é a principal contribuição deste artigo. A literatura brasileira sobre os determinantes do voto é extensa e elucidativa quanto à compreensão da escolha dos eleitores. Contudo, ela não é vasta na utilização dos sentimentos como variáveis que explicam a decisão dos eleitores.

\section{Os sentimentos e os eleitores}

Eventos e informaçôes podem provocar emoção nos indivíduos e, por consequência, sentimentos. A relação ambiente-corpo-mente-cérebro-organismo possibilita a emoção e o sentimento. As emoçôes são efêmeras. Sentimentos são duradouros (DAMÁSIO, 1996; LE BRETON, 2009; SAMPAIO, 2014; THAMM, 2006).

Os sentimentos já podem estar presentes nos indivíduos, e diante de algum evento, eles sentem emoção em razão do sentimento presente. Porém, as emoções dos indivíduos podem surgir diante da ausência de sentimentos, e não se transformarem em sentimentos. Ou podem vir a originar sentimentos (DAMÁSIO, 1996).

Elster (1997 e 1998), Le Breton (2009), Rezende e Coelho (2010) e Thamm (2006) não diferenciam sentimentos das emoções. Ambos representam, segundo eles, a mesma categoria. Sentimentos ou emoçóes dirigidos a alguma coisa e evento surgem no ambiente social. Normas sociais, crenças e valores conduzem a formação dos sentimentos ou das emoçóes dos indivíduos. Diante do sentimento ou emoção sentida por algo, os indivíduos reagem com gestos e verbalizaçóes (ELSTER, 1997 e 1998; LE BRETON, 2009; REZENDE e COELHO, 2010; SAMPAIO, 2014; THAMM, 2006).

Não promovemos neste artigo a discussão teórica entre as categorias emoções e sentimentos. Acatamos os argumentos de Damásio (1996), Elster (1997 e 1998), Le Breton (2009) e Rezende e Coelho (2010) quanto à essência dos sentimentos e das emoções, porém não as distinguimos.

Portanto, sentimentos e emoçóes nascem da relação do indivíduo com o ambiente social no qual ele está inserido - argumento de Elster (1997 e 1998), Le Breton (2009), Rezende e Coelho (2010), Sampaio (2014) e Thamm (2006); e da 
relação ambiente-corpo-mente-cérebro-organismo, argumento de Damásio (1996). Nesse sentido, ambas as categorias se completam.

Boudon (1995) e Mises (1966) procuram decifrar a ação dos indivíduos. Segundo esses autores, os indivíduos fazem escolhas, portanto agem. Eles agem em virtude de quê? Damásio (1996), Elster (1997), Lavareda (2011), Le Breton (2009), Pimentel Júnior (2007 e 2010) e Solomon (2015) frisam que os sentimentos dos indivíduos são variáveis que condicionam ou orientam a tomada de decisão dos indivíduos. Portanto, os sentimentos provocam (causa) e condicionam a ação dos indivíduos.

$\mathrm{O}$ ambiente social condiciona a ação dos indivíduos. Eventos e instituições que estão presentes no ambiente podem incentivar a tomada de decisão dos indivíduos, os quais estão a percorrer uma trajetória (AOKI, 2007; HALL e TAYLOR, 2003). Desse modo, indivíduos criam sentimentos por algo no transcurso da trajetória e, por consequência, agem, fazem escolhas (ELSTER, 1997; OLIVEIRA, 2014).

\section{Saudade, entusiasmo e medo}

Os indivíduos podem ter saudade de algo ou de um evento. Esse sentimento sugere a lembrança do convívio com algo (SAMPAIO, 2014). A saudade é um sentimento que nasce da lembrança, da experiência e da vivência do indivíduo em relação a algo na sua trajetória de vida (DAMATTA, 1993). Se os indivíduos sentem saudade em razão da lembrança, isso significa que determinados eventos estão presentes em sua memória constante ou esporadicamente e podem motivar lembrança e saudades. Motivados pela saudade, esses indivíduos podem agir em busca de algo (DAMATTA, 1993).

A lembrança de algo por parte do indivíduo não indica, necessariamente, que ele conviveu com dada pessoa ou vivenciou certa situaçáo social. A saudade de eventos, coisas, gostos, pessoas, lugares e relaçóes independem da experiência com eles. A saudade de algo também advém da produção social (DAMATTA, 1993).

Tem-se a premissa de que eleitores sentem saudades de certo ator político. Tal fato pode ser observado quando candidatos disputam a reeleição, quando competem novamente. Desse modo, se o competidor que disputa a reeleição vier a perdê-la, os eleitores poderão sentir saudades dele, não sentir ou ficar indiferentes. Se o candidato já tiver sido presidente da República e disputar novamente a eleiçáo para a Presidência, uma parte expressiva dos eleitores poderá escolhê-lo novamente por sentirem saudade. 
Eventos constroem sentimentos de entusiasmo. Pimentel Júnior (2010) frisa que indivíduos, diante das circunstâncias nas quais estấo os eventos, podem ter entusiasmo para fazer algo, no caso, agir, mas para tal ação ocorrer, a memória sobre algo precisa estar ativa, ou seja, existir uma predisposição. Nesse sentido, o agir entusiasmado pode consolidar hábitos (repetir a ação) e possibilitar novas açóes.

Se o entusiasmo estiver associado à memoria, assim sendo, construímos a seguinte premissa: eleitores têm entusiasmo para votar em dado competidor. $O$ entusiasmo advém, então, da memória positiva (boa lembrança) que parte dos eleitores tem em relação ao candidato. A memória positiva existe em virtude de que o presidenciável foi um bom presidente da República, por exemplo.

Em contextos de reeleição, eleitores têm entusiasmo para votar em candidatos à reeleição caso estes provoquem boas lembranças aos sufragistas. Por outro lado, se a memória do eleitor referente ao candidato à reeleição incentivar más lembranças, os sufragistas adquirem entusiasmo para escolherem candidatos da oposição.

Eventos ocorridos ou que estáo para ocorrer podem provocar o sentimento de medo no indivíduo. Tal sentimento, assim como outros já apresentados, surgem da experiência ou do ouvir dizer. $\mathrm{O}$ medo sugere rejeição a algo que tenha ocorrido, que vigora no presente ou poderá existir (BAUMAN, 2008; DAMÁSIO, 1996; LE BRETON, 2009; PIMENTEL JÚNIOR, 2010; REZENDE e COELHO, 2010; SOLOMON, 2015).

Medo sugere incerteza quanto à possível ocorrência de algo ou quanto à dúvida de que ele vai ocorrer (BAUMAN, 2008). Por exemplo: medo de perder o emprego ou do aumento de impostos (DELUMEAU, 1989). A incerteza poderá existir entre os indivíduos em razão de uma experiência vivida que foi ruim e eles não desejam vivenciar novamente.

Nesse sentido, diante da experiência negativa passada, os indivíduos passam a temer o futuro, por isso rejeitam a possibilidade de nova experiência. Portanto, sentir medo é temer um futuro perigoso, incerto (BAUMAN, 2008; DELUMEAU, 1989).

Tem-se a premissa, portanto, de que eleitores rejeitam, ou melhor, sentem medo de candidatos a presidente da República. Assim sendo, eleitores podem temer a reeleição do presidente ou a vitória da oposição. Se eleitores temem a reeleição do presidente, eles expressam receio quanto ao futuro em razão da experiência negativa com o presidente atual. Porém, caso eles expressem medo diante do sucesso eleitoral da oposição, ficam incertos quanto ao que virá, por exemplo, temem a perda de conquistas adquiridas no período do presidente náo reeleito. 


\section{As escolhas dos eleitores}

Considerando os sentimentos apresentados, analisamos o desempenho da candidata à reeleição à Presidência da República, Dilma Rousseff, no estado de Pernambuco, com o objetivo de verificar a seguinte hipótese:

- Os sentimentos medo, entusiasmo e saudade são variáveis independentes que motivam o voto ou o náo voto (variáveis dependentes) nos competidores.

A comprovação ou a falsificação da hipótese apresentada indicará a capacidade explicativa dos sentimentos saudade, entusiasmo e medo. Porém, antes disso, as seguintes condiçóes precisam estar presentes para que a capacidade explicativa dos sentimentos seja avaliada. As condiçốes são:

1. os sentimentos precisam ser observados em série, ou seja, em um conjunto de pesquisas antes do dia da eleição;

2. observação em série da força da associação estatística entre os sentimentos sugeridos e as intençôes de voto;

3. a regularidade e a força das associaçóes estatísticas entre sentimentos e intençốes de voto sugerem causalidades. Se regularidade e associaçóes existem, mesmo com pequenas variaçóes na série observada, está-se diante de condições adequadas para confirmação da hipótese sugerida.

\section{A análise dos dados}

A presidente Dilma Rousseff será candidata à reeleição neste ano. Se ela não vencer a eleição, ela deixará...? Diante dessa pergunta, constatamos, na série de pesquisas mostradas no Gráfico 1, que os sufragistas, majoritariamente, não sentirão saudades da candidata Dilma Rousseff, caso ela não seja reeleita. Entretanto, ao longo da série, tal variável apresenta variações negativas, ao contrário da variável "sentir saudades". A variável "intenção de voto" em Dilma Rousseff expóe, assim como a variável "sentir saudades", crescimento. Portanto, os dados mostram que ao longo da trajetória eleitoral a candidata do PT conquistou eleitores. 
Gráfico 1 - Sentimento saudade e intenção de voto em Dilma Rousseff

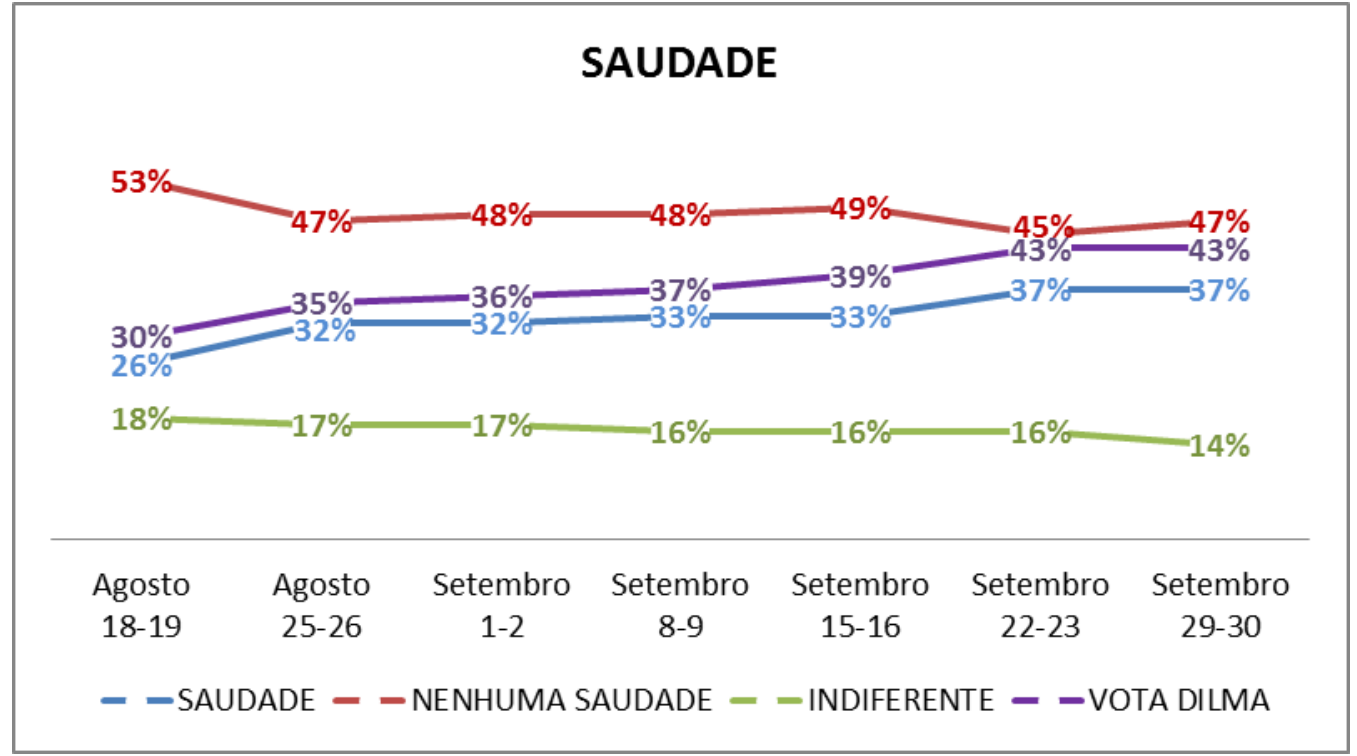

Fonte: Instituto de Pesquisa Maurício de Nassau e Cenário Inteligência (2014).

Fenômeno semelhante observamos no Gráfico 2, que mostra o comportamento da variável entusiasmo - Este ano haverá eleição para presidente da República. Desse modo, você está entusiasmado para votar? A variável "entusiasmo em votar na situação", no caso, na reeleição da presidente Dilma Rousseff, na série pesquisada, apresenta-se em constante crescimento.

E a variável "entusiasmo em votar na oposição" tem pequenas variaçóes, mas na última pesquisa, constata-se o declínio do porcentual de eleitores dispostos a votar em candidatos da oposição a Dilma Rousseff. Sendo assim, esses dados mostram que a candidata do PT conquistou eleitores ao longo da jornada eleitoral. 
Gráfico 2 - Sentimento entusiasmo e intenção de voto em Dilma Rousseff

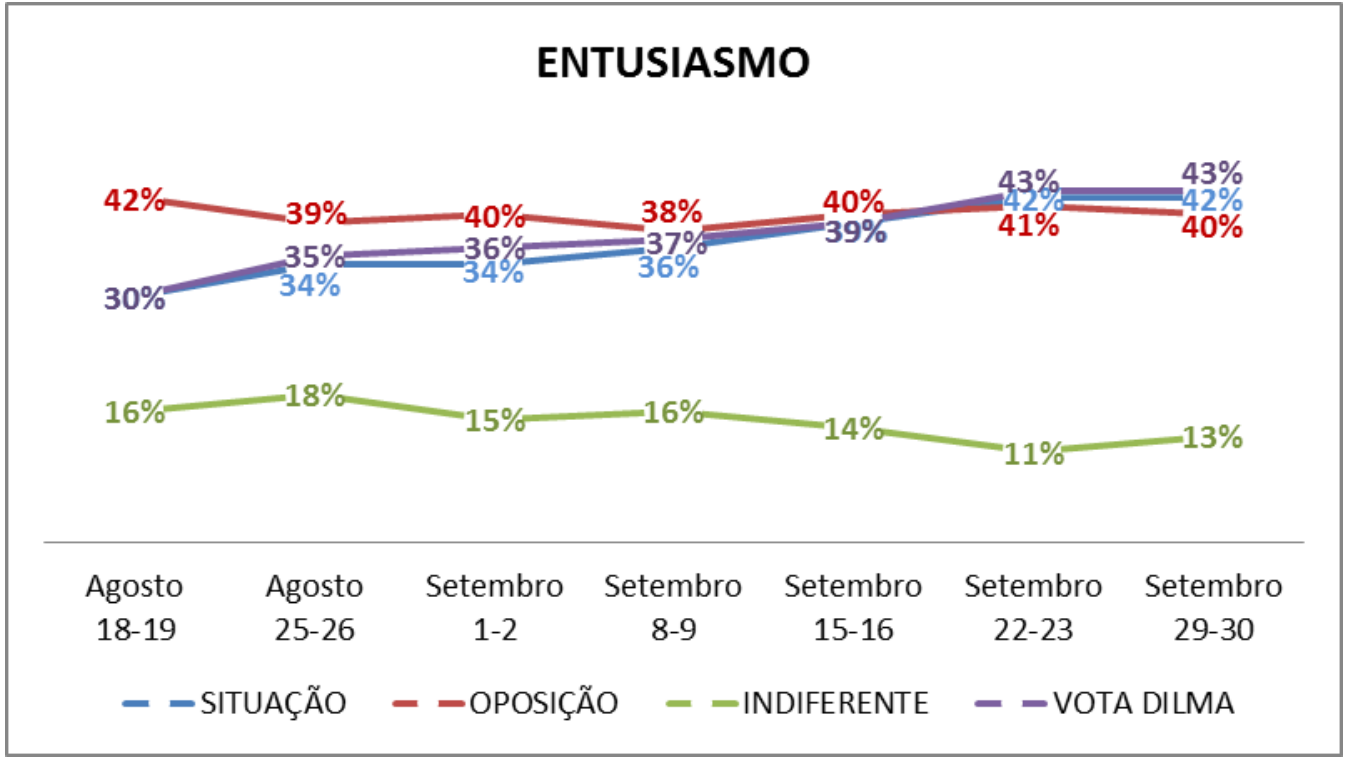

Fonte: Instituto de Pesquisa Maurício de Nassau e Cenário Inteligência (2014).

Qual destes politicos você tem medo que venha a ser presidente do Brasil? Ao contrário das outras variáveis, a variável "medo" em relação a Dilma Rousseff apresenta pequenas variaçóes, que sugerem estabilidade na série (Gráfico 3). Em relação à candidata Marina Silva (PSB), principal oposicionista de Dilma Rousseff em Pernambuco, constatamos variação positiva da variável "medo" ao longo da série.

Tal fator náo coincide com o porcentual de eleitores dispostos a votar nela. Inicialmente, a intenção de votos em Marina sofre declínio. Em seguida, constata-se a estabilidade. Entretanto, os dados em série sugerem que o aumento do sentimento medo por parte dos eleitores em relaçáo a Marina impossibilitou sua recuperaçáo eleitoral ${ }^{3}$.

${ }^{3}$ No primeiro turno da eleição presidencial, a candidata Marina Silva obteve, em Pernambuco, 48,05\% dos votos válidos, e a candidata Dilma Rousseff, 44,22\%. Em razão destes resultados, opta-se por analisar o comportamento dos eleitores em relação a estes candidatos. 
Gráfico 3 - Sentimento medo e intenção de voto em Dilma Rousseff e Marina Silva

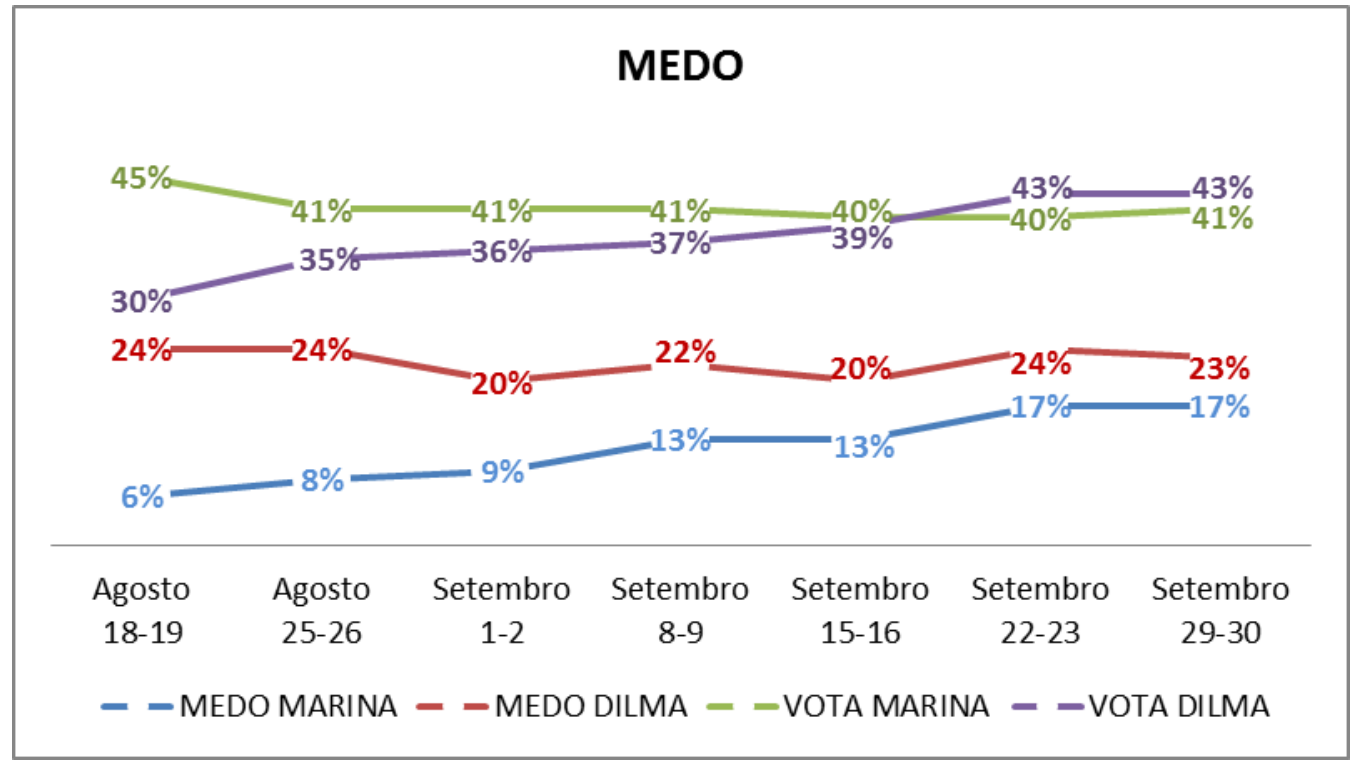

Fonte: Instituto de Pesquisa Maurício de Nassau e Cenário Inteligência (2014).

O comportamento dos sentimentos saudade e entusiasmo, observados em série nos gráficos, mostra a recuperação contínua da candidata Dilma Rousseff na trajetória eleitoral. Tais indicadores sempre foram porcentualmente superiores aos que fazem referência à oposição a Dilma Rousseff. Portanto, as variáveis "entusiasmo" e "saudade", quando observadas sistematicamente na trajetória eleitoral, sugerem a possibilidade de sucesso eleitoral da presidente candidata à reeleição.

$\mathrm{Na}$ série de pesquisas, constatamos o aumento do porcentual de eleitores com medo de votar em Dilma Rousseff e em Marina Silva. O crescimento dessa variável na série de pesquisas sugere que ela ocasionou a interrupção da trajetória de crescimento de ambas as candidatas.

\section{A força explicativa dos sentimentos}

Para complementar a análise estatística descritiva e buscar mais elementos para comprovarmos a hipótese deste artigo, utilizamos, inicialmente, o teste estatístico Qui-Quadrado de Pearson com o objetivo de verificar a existência de associação entre as variáveis sentimentos e intenção de votos.

Todas as relações testadas apresentaram associação com nível de significância de $\mathrm{p}<0,001$ - Cf. Tabelas 1, 2 e 3. Isso significa, então, que as variáveis "sentimentos" e "intenção de voto", estão associadas. Utilizamos também o coeficiente de correlação 
Cramer's V com o objetivo de verificar a força dessa associação. Esse coeficiente varia entre 0 e 1; quando está próximo de 0 , indica uma fraca associação e quanto mais próximo de 1 , mais forte é a associação.

A Tabela 1 mostra que existe associação significativa entre o sentimento saudade e intençáo de voto. $\mathrm{Na}$ primeira pesquisa apresentada na Tabela 1, observamos que dos eleitores que declararam sentir saudade da candidata do PT, caso ela perca a eleição, votam nela $86,7 \%$ para presidente da República. Nas pesquisas seguintes, observamos os porcentuais $89,9 \%, 91,5 \%, 94,2 \%$ e $93,5 \%$.

No âmbito da candidata Marina Silva, constatamos, na primeira pesquisa, que no universo dos eleitores que declararam não sentir, saudades caso Dilma Rousseff não seja reeleita, votam $73,2 \%$ em Marina Silva. As pesquisas posteriores apresentam os porcentuais $73,6 \%, 77,5 \%, 75,4 \%$ e $78,4 \%$. 
Tabela 1 - Sentimento que a presidente Dilma deixará se não for reeleita

\begin{tabular}{|c|c|c|c|c|c|}
\hline \multirow[t]{2}{*}{$\begin{array}{c}\text { Intençáo de } \\
\text { voto }\end{array}$} & \multicolumn{3}{|c|}{$\begin{array}{l}\text { A presidente Dilma será candidata à } \\
\text { reeleiçáo na disputa presidencial deste } \\
\text { ano. Se ela náo vencer a eleiçáo, ela } \\
\text { deixará: }\end{array}$} & \multirow[t]{2}{*}{$\begin{array}{l}\text { Valor de } \mathrm{p} \\
\qquad\left(^{*}\right)\end{array}$} & \multirow[t]{2}{*}{ Cramer's V } \\
\hline & Saudades & $\begin{array}{l}\text { Nenhuma } \\
\text { saudade }\end{array}$ & Indiferente & & \\
\hline \multicolumn{6}{|c|}{ Agosto 18-19 } \\
\hline Dilma & 86,7 & 8,2 & 33,5 & 0,000 & 0,507 \\
\hline Marina & 11,3 & 73,2 & 51,6 & & \\
\hline Outros & 0,8 & 6,8 & 4,1 & & \\
\hline $\begin{array}{c}\text { Em } \\
\text { branco/nulo }\end{array}$ & 1,2 & 11,7 & 10,8 & & \\
\hline \multicolumn{6}{|c|}{ Agosto 25-26 } \\
\hline Dilma & 89,9 & 5,1 & 29,8 & 0,000 & 0,562 \\
\hline Marina & 6,3 & 73,6 & 50,0 & & \\
\hline Outros & 1,8 & 8,6 & 5,6 & & \\
\hline $\begin{array}{l}\text { Em } \\
\text { branco/nulo }\end{array}$ & 2,0 & 12,6 & 14,6 & & \\
\hline \multicolumn{6}{|c|}{ Setembro 1-2 } \\
\hline Dilma & 91,5 & 4,4 & 36,5 & 0,000 & 0,575 \\
\hline Marina & 5,8 & 77,5 & 45,6 & & \\
\hline Outros & 1,3 & 3,9 & 3,8 & & \\
\hline $\begin{array}{l}\text { Em } \\
\text { branco/nulo }\end{array}$ & 1,4 & 14,1 & 14,2 & & \\
\hline \multicolumn{6}{|c|}{ Setembro $15-16$} \\
\hline Dilma & 94,2 & 6,2 & 43,2 & 0,000 & 0,580 \\
\hline Marina & 4,8 & 75,4 & 35,7 & & \\
\hline Outros & 0,6 & 5,6 & 7,8 & & \\
\hline $\begin{array}{l}\text { Em } \\
\text { branco/nulo }\end{array}$ & 0,4 & 12,9 & 13,4 & & \\
\hline \multicolumn{6}{|c|}{ Setembro $29-30$} \\
\hline Dilma & 93,5 & 6,0 & 47,1 & 0,000 & 0,578 \\
\hline Marina & 4,5 & 78,4 & 38,2 & & \\
\hline Outros & 1,0 & 7,4 & 5,1 & & \\
\hline $\begin{array}{l}\text { Em } \\
\text { branco/nulo }\end{array}$ & 1,0 & 8,2 & 9,6 & & \\
\hline
\end{tabular}

(*) Teste qui-quadrado de independência.

Fonte: Instituto de Pesquisa Maurício de Nassau e Cenário Inteligência (2014). 
O coeficiente de correlação Cramer's V no lado direito da Tabela 1 mostra que a associação é relativamente forte entre a variável saudade e intenção de voto ${ }^{4}$. Tal resultado, ao ser observado em série, sugere que essa variável contribui para explicar a escolha dos eleitores, em virtude da regularidade quanto à força da associaçáo entre as variáveis nas rodadas de pesquisas analisadas.

Existe associação significativa entre o sentimento entusiasmo e intençôes de voto dos competidores à Presidência da República. O valor da estatística Cramer's V mais alto, indica que essas variáveis têm uma forte associação ${ }^{5}$. A Tabela 2 mostra que dos sufragistas que declaram estar entusiasmados em votar no candidato da situação, optam 94,2\% por Dilma Rousseff - pesquisa 18 e 19 de agosto. As outras pesquisas mostram os porcentuais $94,2 \%, 96,7 \%, 97,3 \%, 98,1 \%$ e $98,9 \%$.

No universo dos que declaram estar entusiasmados em votar em um candidato de oposição à presidente Dilma Rousseff, optam $88,7 \%$ por votar em Marina Silva - pesquisa 18 e 19 de agosto. Os porcentuais ao longo da série de pesquisa são $88,7 \%, 87,1 \%, 91,3 \%, 90,7 \%$ e 89,2\%. Assim como a variável "saudade", o sentimento entusiasmo, ao ser observado em série, possibilita a explicação da escolha dos eleitores.

\footnotetext{
${ }^{4}$ Verificar quadrante do lado direito na Tabela 1.

${ }^{5}$ Verificar quadrante do lado direito na Tabela 2.
} 
Tabela 2 - Entusiasmo do eleitor em votar na presidente Dilma ou em candidato de oposição

\begin{tabular}{|c|c|c|c|c|c|}
\hline \multirow[t]{2}{*}{$\begin{array}{l}\text { Intençáo de } \\
\text { voto }\end{array}$} & \multicolumn{3}{|c|}{$\begin{array}{c}\text { Este ano haverá eleiçáo para a Presidência da } \\
\text { República. Desse modo, você está } \\
\text { ENTUSIASMADO para votar: }\end{array}$} & \multirow[t]{2}{*}{$\begin{array}{l}\text { Valor de } \mathrm{p} \\
\left({ }^{*}\right)\end{array}$} & \multirow[t]{2}{*}{ Cramer's V } \\
\hline & $\begin{array}{l}\text { na presidente } \\
\text { Dilma }\end{array}$ & \begin{tabular}{|l|} 
em um \\
candidato de \\
OPOSIÇÃO à \\
presidente \\
Dilma
\end{tabular} & Indiferente & & \\
\hline \multicolumn{6}{|c|}{ Agosto 18-19 } \\
\hline Dilma & 94,2 & 1,7 & 9,9 & 0,000 & 0,716 \\
\hline Marina & 4,1 & 88,7 & 46,0 & & \\
\hline Outros & 0,7 & 6,3 & 8,3 & & \\
\hline Em branco/nulo & 1,0 & 3,3 & 35,8 & & \\
\hline \multicolumn{6}{|c|}{ Agosto 25-26 } \\
\hline Dilma & 96,7 & 1,0 & 11,3 & 0,000 & 0,732 \\
\hline Marina & 1,1 & 87,1 & 46,7 & & \\
\hline Outros & 1,6 & 9,0 & 7,1 & & \\
\hline Em branco/nulo & 0,6 & 2,9 & 34,8 & & \\
\hline \multicolumn{6}{|c|}{ Setembro 1-2 } \\
\hline Dilma & 97,3 & 1,6 & 13,3 & 0,000 & 0,769 \\
\hline Marina & 1,3 & 91,3 & 35,3 & & \\
\hline Outros & 0,8 & 4,1 & 5,0 & & \\
\hline Em branco/nulo & 0,5 & 3,0 & 46,4 & & \\
\hline \multicolumn{6}{|c|}{ Setembro $15-16$} \\
\hline Dilma & 98,1 & 0,6 & 17,4 & 0,000 & 0,804 \\
\hline Marina & 1,1 & 90,7 & 25,3 & & \\
\hline Outros & 0,4 & 6,9 & 6,8 & & \\
\hline Em branco/nulo & 0,4 & 1,8 & 50,6 & & \\
\hline \multicolumn{6}{|c|}{ Setembro $29-30$} \\
\hline Dilma & 98,9 & 0,5 & 14,1 & 0,000 & \\
\hline Marina & 0,8 & 89,2 & 47,0 & & \\
\hline Outros & 0,2 & 1,3 & 6,0 & & \\
\hline Em branco/nulo & 0,1 & 9,0 & 32,9 & & \\
\hline
\end{tabular}

(*) Teste qui-quadrado de independência.

Fonte: Instituto de Pesquisa Maurício de Nassau e Cenário Inteligência (2014).

Medo e intenção do voto são variáveis que também estão associadas. No entanto, o valor da estatística Cramer's $\mathrm{V}$ indica associação fraca entre essas variáveis. Porém, ainda assim, existe associação. Então o consideramos também como variável que explica o comportamento dos eleitores, em particular, no que condiz à limitação de crescimento eleitoral por parte de Dilma Rousseff e Marina Silva. 
A Tabela 3 revela que, na primeira pesquisa (18 e 19 de agosto), os eleitores que declaram ter medo de Dilma Rousseff votam majoritariamente em Marina Silva, $79,4 \%$. Essa associação é observada também nas pesquisas seguintes: 81,9\%, 90,9\%, $87 \%$ e $88 \%$. Os sufragistas que têm medo de outros competidores votam majoritariamente em Dilma Rousseff.

Tabela 3 - Medo do eleitor em votar na presidente Dilma ou em candidato de oposiçāo

\begin{tabular}{|c|c|c|c|c|c|}
\hline \multirow[t]{2}{*}{ Intençáo de voto } & \multicolumn{3}{|c|}{$\begin{array}{l}\text { Qual destes políticos você tem MEDO de que } \\
\text { venha a ser presidente do Brasil? }\end{array}$} & \multirow[t]{2}{*}{$\begin{array}{l}\text { Valor de } \mathrm{p} \\
\left(^{*}\right)\end{array}$} & \multirow[t]{2}{*}{ Cramer's V } \\
\hline & Dilma & Outros & Nenhum & & \\
\hline \multicolumn{6}{|c|}{ Agosto $18-19$} \\
\hline Dilma & 7,6 & 51,9 & 34,6 & 0,000 & 0,328 \\
\hline Marina & 79,4 & 4,20 & 43,2 & & \\
\hline Outros & 6,3 & 4,5 & 3,1 & & \\
\hline Em branco/nulo & 6,7 & 1,6 & 19,1 & & \\
\hline \multicolumn{6}{|c|}{ Agosto 25-26 } \\
\hline Dilma & 5,1 & 60,4 & 39,2 & 0,000 & 0,412 \\
\hline Marina & 81,9 & 33,5 & 34,2 & & \\
\hline Outros & 9,0 & 3,8 & 3,8 & & \\
\hline Em branco/nulo & 3,9 & 2,2 & 22,8 & & \\
\hline \multicolumn{6}{|c|}{ Setembro $1-2$} \\
\hline Dilma & 1,9 & 61,3 & 41,4 & 0,000 & 0,379 \\
\hline Marina & 90,9 & 29,7 & 39,0 & & \\
\hline Outros & 2,1 & 3,5 & 2,6 & & \\
\hline Em branco/nulo & 5,1 & 5,6 & 17,0 & & \\
\hline \multicolumn{6}{|c|}{ Setembro $15-16$} \\
\hline Dilma & 1,5 & 69,7 & 40,3 & 0,000 & 0,409 \\
\hline Marina & 87,0 & 24,7 & 39,9 & & \\
\hline Outros & 6,7 & 3,0 & 3,9 & & \\
\hline Em branco/nulo & 4,8 & 2,6 & 15,8 & & \\
\hline \multicolumn{6}{|c|}{ Setembro $29-30$} \\
\hline Dilma & 2,7 & 69,2 & 44,0 & 0,000 & 0,435 \\
\hline Marina & 88,0 & 25,2 & 38,4 & & \\
\hline Outros & 7,7 & 3,5 & 2,9 & & \\
\hline Em branco/nulo & 1,6 & 2,1 & 14,8 & & \\
\hline
\end{tabular}

$\left.{ }^{*}\right)$ Teste qui-quadrado de independência.

Fonte: Instituto de Pesquisa Maurício de Nassau e Cenário Inteligência (2014).

Utilizamos também modelos de regressão logística multinomial para explicar o voto em cada candidato nas cinco rodadas de pesquisas avaliadas a fim de oferecer mais subsídios para a comprovação da hipótese deste artigo. Considerando a natureza 
dos dados, tal modelo é adequado, pois a variável dependente é nominal e assume diversos valores que identificam a intenção de voto dos entrevistados.

No modelo multinomial, estimam-se os efeitos das covariáveis para cada uma das equaçóes em relação a uma categoria-base. No modelo proposto, analisaram-se as intençôes de voto em Dilma, Marina e "em branco/nulo" em relação à base de comparação "outros".

A Tabela 4 apresenta os coeficientes do modelo de regressão estimado, bem como o indicativo do seu nível de significância. Tais coeficientes representam o efeito da categoria da variável em questáo em relação à categoria de referência na variável dependente. Para uma interpretação mais direta, é possível obter os valores dos odds ratios (razão de chances ou razão de riscos relativos) estimados, calculados pela função exponencial dos coeficientes estimados dos betas, $\exp (\mathrm{b})$.

A análise das regressões das rodadas de pesquisa mostra que a variável "entusiasmo" se destaca em relaçáo às demais. Tal como se pode observar na Tabela 4, em praticamente todas as rodadas de pesquisa e categoria de análise, essa é a variável que apresenta o maior coeficiente beta de regressão.

Os eleitores que se dizem entusiasmados para votar em Dilma estáo bastante propensos a votar na candidata quando comparados com os eleitores que se dizem indiferentes. O menor coeficiente, 2,822, ocorre na pesquisa de 1-2 setembro, indicando que o eleitor entusiasmado para votar na presidente tem 16,78 - exp $(2,822)$ - vezes mais chances de votar na presidente que em outro candidato. Por parte dos eleitores que estão entusiasmados para votar na oposição, os coeficientes indicam uma preferência por Marina a outro candidato se comparados com aqueles que se disseram indiferentes. 
Tabela 4 - Modelo de regressão logística multinomial - Coeficientes: base comparativa

\begin{tabular}{|c|c|c|c|c|c|c|}
\hline Variáveis & Categorias de Análise & 18-19 ago. & 25.26 ago. & $1-2$ set. & $15-16$ set. & $29-30$ set. \\
\hline \multicolumn{7}{|c|}{ Dilma } \\
\hline Intercept & - & 0,509 & 0,644 & $1,339^{* *}$ & $0,745^{*}$ & $1,507^{* * *}$ \\
\hline \multirow{2}{*}{$\begin{array}{l}\text { Medo } \\
\text { (Outros) }\end{array}$} & Dilma & $-0,528$ & $-0,502$ & 0,091 & $-1,899^{* *}$ & $-1,473^{* *}$ \\
\hline & Nenhum & $-0,008$ & 0,294 & 0,546 & 0,568 & 0,074 \\
\hline \multirow[t]{2}{*}{$\begin{array}{l}\text { Saudade } \\
\text { (Indiferente) }\end{array}$} & $\begin{array}{l}\text { Vai deixar } \\
\text { saudades }\end{array}$ & 0,458 & 0,602 & $1,089^{*}$ & 0,917 & $-0,462$ \\
\hline & $\begin{array}{l}\text { Náo vai deixar } \\
\text { saudades }\end{array}$ & $-0,574$ & $-1,685^{* * *}$ & $-1,575^{* * *}$ & $-0,290$ & $-0,640$ \\
\hline \multirow[t]{2}{*}{$\begin{array}{l}\text { Entusiasmo } \\
\text { (Indiferente) }\end{array}$} & $\begin{array}{l}\text { Entusiasmado para } \\
\text { Dilma }\end{array}$ & $4,900^{* * *}$ & $3,151^{* * *}$ & $2,822^{* * *}$ & $3,841^{* * *}$ & $5,069^{* * *}$ \\
\hline & $\begin{array}{l}\text { Entusiasmado para } \\
\text { oposição }\end{array}$ & $-1,109^{* *}$ & $-1,470^{* * *}$ & $-1,822^{* * *}$ & $-3,107^{* * *}$ & $-3,589^{* * *}$ \\
\hline \multicolumn{7}{|c|}{ Marina } \\
\hline Intercept & - & $1,883^{* * *}$ & $2,106^{* * *}$ & $2,026^{* * *}$ & $0,634^{*}$ & $1,547^{* * *}$ \\
\hline \multirow{2}{*}{$\begin{array}{l}\text { Medo } \\
\text { (Outros) }\end{array}$} & Dilma & $-0,051$ & $-0,339$ & $1,259^{* * *}$ & 0,190 & 0,314 \\
\hline & Nenhum & 0,124 & $-0,182$ & 0,289 & 0,049 & $0,587^{*}$ \\
\hline \multirow[t]{2}{*}{$\begin{array}{l}\text { Saudade } \\
\text { (Indiferente) }\end{array}$} & $\begin{array}{l}\text { Vai deixar } \\
\text { saudades }\end{array}$ & 0,351 & $-0,061$ & $-0,235$ & 0,687 & $-0,270$ \\
\hline & $\begin{array}{l}\text { Náo vai deixar } \\
\text { saudades }\end{array}$ & $-0,112$ & 0,059 & $-0,244$ & $0,931^{* * *}$ & 0,500 \\
\hline \multirow[t]{2}{*}{$\begin{array}{l}\text { Entusiasmo } \\
\text { (Indiferente) }\end{array}$} & $\begin{array}{l}\text { Entusiasmado para } \\
\text { Dilma }\end{array}$ & 0,395 & $-2,552^{* * *}$ & $-1,483^{* *}$ & $-0,454$ & $-0,450$ \\
\hline & $\begin{array}{l}\text { Entusiasmado para } \\
\text { oposição }\end{array}$ & $0,918^{* * *}$ & $0,461^{*}$ & $0,795^{* *}$ & $1,066^{* * *}$ & 0,128 \\
\hline \multicolumn{7}{|c|}{ Em branco/nulo } \\
\hline Intercept & - & $-0,381$ & 0,154 & $1,378^{* *}$ & 0,001 & 0,237 \\
\hline \multirow{2}{*}{$\begin{array}{l}\text { Medo } \\
\text { (Outros) }\end{array}$} & Dilma & $0,932^{*}$ & $-0,461$ & 0,362 & $-0,137$ & $-0,685$ \\
\hline & Nenhum & $2,487^{* * *}$ & $2,043^{* * *}$ & $1,368^{* * *}$ & $1,853^{* * *}$ & $2,610^{* * *}$ \\
\hline \multirow[t]{2}{*}{$\begin{array}{l}\text { Saudade } \\
\text { (Indiferente) }\end{array}$} & $\begin{array}{l}\text { Vai deixar } \\
\text { saudades }\end{array}$ & $-0,278$ & $-0,698$ & $-0,577$ & $-0,844$ & $-0,166$ \\
\hline & $\begin{array}{l}\text { Não vai deixar } \\
\text { saudades }\end{array}$ & 0,461 & $0,826^{* *}$ & 0,634 & $1,478^{* * *}$ & $0,845^{*}$ \\
\hline \multirow[t]{2}{*}{$\begin{array}{l}\text { Entusiasmo } \\
\text { (Indiferente) }\end{array}$} & $\begin{array}{l}\text { Entusiasmado para } \\
\text { Dilma }\end{array}$ & $-0,148$ & $-2,314^{* * *}$ & $-2,598^{* * *}$ & $-0,943$ & $-2,265^{*}$ \\
\hline & $\begin{array}{l}\text { Entusiasmado para } \\
\text { oposiçáo }\end{array}$ & $-2,001^{* * *}$ & $-2,741^{* * *}$ & $-2,965^{* * *}$ & $-3,363^{* * *}$ & $-3,810^{* * *}$ \\
\hline \multicolumn{2}{|l|}{ Obs. válidas } & 1.684 & 1.816 & 1.850 & 2.021 & 2.092 \\
\hline \multicolumn{2}{|l|}{$\mathrm{Chi}^{2}$} & $\begin{array}{c}1924,17 \\
\text { (18g.l.,sig.= } \\
0,00)\end{array}$ & $\begin{array}{c}2361,96 \\
(18 \text { g.l.,sig.= } \\
0,00)\end{array}$ & $\begin{array}{c}2499,42 \\
\text { (18g.l.,sig.= } \\
0,00)\end{array}$ & $\begin{array}{c}2859,28 \\
(18 \mathrm{~g} .1 ., \mathrm{sig} \\
.=0,00)\end{array}$ & $\begin{array}{c}2890,99 \\
(18 \mathrm{~g} .1 ., \mathrm{sig} \\
.=0,00)\end{array}$ \\
\hline \multicolumn{2}{|c|}{ Pseudo $\mathrm{R}^{2}$ de McFadden } & 0,551 & 0,604 & 0,663 & 0,682 & 0,695 \\
\hline
\end{tabular}

Obs: Significância $1 \%\left({ }^{* * *}\right), 5 \%\left({ }^{* *}\right)$ e $10 \%\left(^{*}\right)$.

Fonte: Instituto de Pesquisa Maurício de Nassau e Cenário Inteligência (2014). 
Para os eleitores que pretendem votar em branco/nulo, os coeficientes apresentaram valores negativos para as duas categorias de análise, ou seja, diminuem as chances dos votos em branco/nulo quando os eleitores estáo entusiasmados em votar em Dilma ou na oposição.

Para a variável "saudade", na comparação entre Dilma Rousseff e outro candidato, a presidente é desfavorecida pelos eleitores que afirmam que ela não vai deixar saudades. Há cerca de $80 \%$ menos chance de esses eleitores escolherem votar na candidata à reeleição. Já em relação a Marina, há 2,5 vezes mais chance de ser escolhida pelos eleitores que afirmam que a presidente Dilma Rousseff não vai deixar saudades do que outro candidato. Para esse mesmo grupo de eleitores, pode chegar a 4,4 vezes mais chance de votar em branco/nulo do que em outro candidato.

A variável "medo" mostra que os eleitores que dizem ter medo de votar em Dilma Rousseff estão propensos a não votar na candidata; os coeficientes foram significativos nas duas rodadas de pesquisa mais próximas do pleito eleitoral. Em uma das rodadas de pesquisa, também é possível observar que os eleitores que estão com medo de votar em Dilma têm 3,5 - exp $(1,259)$ - vezes mais chance de votar em Marina.

$\mathrm{Na}$ comparação da categoria "em branco/nulo" com outros candidatos, em todas as rodadas de pesquisa, os eleitores que dizem ter medo de nenhum dos candidatos do pleito tem mais chance de escolher a opção em branco/nulo, ou seja, indicando que os eleitores neutros em relação à variável "medo" são os que têm mais chance de ficar indecisos.

\section{Conclusão}

Os sentimentos saudades, entusiasmo e medo, como bem mostram os diversos testes estatísticos, são variáveis independentes que explicam a escolha dos eleitores - variável dependente. Portanto, os variados testes estatísticos comprovam a hipótese deste artigo.

$\mathrm{Na}$ série de pesquisas analisadas estatisticamente, observamos associação entre os sentimentos e a intenção de voto. A força da associação também se constata na série de pesquisas, e a variável "entusiasmo" é o sentimento que tem maior poder de explicaçáo quanto à escolha dos eleitores. A regressáo multinominal realizada comprova tal tese. Porém, a força explicativa do sentimento entusiasmo não retira a contribuição explicativa dos demais sentimentos, saudade e medo.

Ao mostrarmos a contribuiçáo dos sentimentos para a explicação do comportamento do eleitor, sugerimos que as variáveis costumeiramente utilizadas 
pela Ciência Política para explicar a decisão dos sufragistas, como "avaliação da administração" e "bem-estar econômico", não são exclusivas para a compreensão do comportamento eleitoral. Os sentimentos também importam.

Nesse sentido, como diversos estudos mostram, é verdadeira a premissa de que boas administraçóes contribuem para o sucesso eleitoral de candidatos, assim como são verdadeiras as seguintes premissas: 1) candidatos que entusiasmam eleitores tendem a obter sucesso eleitoral; 2) candidatos à reeleição que despertam saudades em sufragistas tendem a vencer a disputa eleitoral; 3) competidores que provocam medo/temor entre os eleitores têm possibilidade de perder votos para candidatos da oposição ou ter limite para o crescimento eleitoral.

Adriano Oliveira é Doutor em Ciência Política pela Universidade Federal de Pernambuco (UFPE) e Professor do Departamento de Ciência Politica da UFPE. E-mail: adrianopolitica@uol.com.br.

- Carlos Gadelha é Mestre em Estatística pela UFPE e Estatístico do Instituto de Pesquisa Maurício de Nassau (IPMN). E-mail: carlos.gadelh@hotmail.com

- Simara Costa é Mestre em Estatística pela Universidade Rural de Pernambuco e Estatística do IPMN. E-mail: simaracosta@hotmail.com

\section{Referências}

AOKI, Masahiko. Endogenizing institutions and institutional changes. Journal of Institutional Economics, v. 3, n. 1, p. 1-31, 2007.

BAUMAN, Zygmunt. O medo líquido. Rio de Janeiro: J. Zahar, 2008.

BOUDON, Raymond. Tratado de sociologia. Rio de Janeiro: J. Zahar, 1995.

CARREIRÃO, Yan de Souza. A decisão do voto nas eleiçôes presidenciais brasileiras. Rio de Janeiro: Fundação Getúlio Vargas, 2002.

DAMÁSIO, António R. O erro de Descartes: emoção, razão e o cérebro humano. São Paulo: Companhia das Letras, 1996.

DAMATTA, Roberto. Em torno da representação de natureza no Brasil: pensamentos, fantasias e divagaçôes. In: DAMATTA, Roberto. Conta de mentiroso: sete ensaios de antropologia brasileira. Rio de Janeiro: Rocco, 1993. p. 17-34. 
DELUMEAU, Jean. História do medo no Ocidente: 1300-1800 uma cidade sitiada. Sáo Paulo: Companhia das Letras, 1989.

ELSTER, Jon. Egonomics: análisis de la interacción entre racionalidad, emoción preferencias y normas sociales en la economia de la acción individual y sus desviaciones. Barcelona: Gedisa, 1997.

. Emotions and economics theory. Journal of Economic Literature, v. 36, p. 47-74, mar. 1998.

HALL, Peter A.; TAYLOR, Rosemary C. R. As três versôes do neoinstitucionalismo. Revista Lua Nova, São Paulo, n. 58, p. 193-223, 2003.

HANSON, Robin. What's wrong with expert predictions? Cato Unbound, 2011. Disponível em: <http://www.cato-unbound.org/issues/july-2011/whats-wrong-expert-predictions>. Acesso em: 20 mar. 2013.

INSTITUTO DE PESQUISA MAURÍCIO DE NASSAU; CENÁRIO DE INTELIGÊNCIA. Pesquisa nos dias 18 e 19/09/2014, 25 e 26/09/2014, 1 e 2/10/2014, 8 e 9/10/2014, 15 e 16/10/2014, 22 e 23/10/2014, 29 e 30/10/2014. Eleiçóes 2014. http://www.institutomauriciodenassau.com.br/www.cenariointeligencia.com.br . Acesso em: 15 nov. 2014.

LAVAREDA, Antonio. Emoçôes ocultas e estratégias eleitorais. Rio de Janeiro: Objetiva, 2009.

. Neuropolítica: o papel das emoçôes e do inconsciente. Dossiê Marketing Politico, n. 90, p. 120-146, jun./ago. 2011.

LE BRETON, David. As paixôes ordinárias: antropologia das emoçôes. Petrópolis, RJ: Vozes, 2009.

LOURENÇO, Luiz Claudio. Abrindo a caixa-preta: da indecisão à escolha: a eleição presidencial de 2002. Tese (Doutorado em Ciência Política) - Instituto Universitário de Pesquisas do Rio de Janeiro, Rio de Janeiro, Iuperj, 2007.

MISES, Ludwig von. Human action: a treatise on economics. 3. ed. Chicago: Contemporary Books, 1966.

OLIVEIRA, Adriano. Da praxeologia do eleitor à ciência eleitoral. In: OLIVEIRA, Adriano (Org.). Eleiçôes não são para principiantes: interpretando eventos eleitorais no Brasil. Curitiba, PR: Juruá, 2014. p. 35-49.

; GADELHA, Carlos. Os sentimentos dos eleitores importam para a explicaçáo do comportamento do eleitor? Em Debate, Belo Horizonte, v. 4, n. 4, p. 54-64, 2012.

PEIXOTO, Vitor; RENNÓ, Lúcio. Mobilidade social ascendente e voto: as eleiçóes presidenciais de 2010 no Brasil. Opiniáa Pública, v. 17, n. 2, p. 304-332, nov. 2011. Disponível em: <http://dx.doi.org/10.1590/S0104-62762011000200002>. Acesso em: 6 fev. 2012.

PIMENTEL JÚNIOR, Jairo Tadeu Pires. Razão e emoção no voto: o caso da eleição presidencial de 2006. 128 f. Dissertação (Mestrado em Ciência Política) - Faculdade de Filosofia, Letras e Ciências Humanas, Universidade de São Paulo, São Paulo, 2007.

. Razão e emoção: o voto na eleição presidencial de 2006. Opinião Pública, Campinas, v. 16, n. 2, p. 516-541, nov. 2010.

REZENDE, Cláudia Barcellos; COELHO, Maria Cláudia. Antropologia das emoçôes. Rio de Janeiro: Ed. da FGV, 2010.

SAMPAIO, Thiago da Silva. Popularidade presidencial: análise dos microfundamentos do suporte público da presidente Dilma Rousseff. Tese (Doutorado em Ciência Política) - Faculdade de Filosofia e Ciências Humanas Universidade Federal de Minas Gerais, Belo Horizonte, 2014. 
212 Adriano Oliveira, Carlos Gadelha e Simara Costa

SINGER, André. Esquerda e direita no eleitorado brasileiro: a identificação ideológica nas disputas presidenciais de 1989 e 1994. São Paulo: Edusp, 2000.

SOLOMON, Robert, C. Fiéis às nossas emoçôes: o que elas realmente dizem. Rio de Janeiro: Civilização Brasileira, 2015.

THAMM, Robert A. The classification of emotions. In: STETS, Jan E.; TURNER, Jonathan H. Handbook of the sociology of emotions. New York: Springer, 2006. p. 11-35.

WESTEN, Drew. O cérebro político. São Paulo: Unianchieta, 2007.

Texto recebido em 14 de outubro de 2015. Aprovado em 24 de abril de 2016. 